\title{
ECO INDÚSTRIA NO BRASIL: UMA CARACTERIZAÇÃO DO SETOR PRODUTOR DE TECNOLOGIAS AMBIENTAIS
}

\author{
Stela Luiza de Mattos Ansanelli ${ }^{1}$ \\ Ícaro Martins ${ }^{2}$ \\ Letícia Silva de Faria ${ }^{3}$
}

\section{Resumo}

O setor produtor de tecnologias ambientais é fundamental para o desenvolvimento econômico e sustentável de um país, mas não há uma definição concisa de tecnologias ambientais nem uma delimitação do setor, o que impõe obstáculos ao avanço das negociações quanto à liberalização comercial dessas tecnologias. Dessa forma, o objetivo deste trabalho foi caracterizar o setor produtor de tecnologias ambientais no Brasil, à luz de estudos já realizados, utilizando como metodologia a pesquisa de campo nas empresas que participam da FIMAI (Feira Internacional de Meio Ambiente Industrial e Sustentabilidade). Alguns resultados demonstraram a manutenção de certos aspectos do setor. Entre esses encontram-se tratamento de efluentes e resíduos como os principais segmentos de atuação, setores poluidores (químico, siderúrgico, alimentício) como os maiores clientes, a regulação ambiental como principal fator determinante e o mercado interno como o predominante. A presença dominante de empresas nacionais e de pequeno/médio porte condiz com o verificado nos anos 2000. Outros resultados trouxeram contribuições importantes, como o elevado esforço inovador das empresas nacionais, a atuação das firmas em tecnologias preventivas e/ou integradoras e a fragilidade de atuação do poder público nas compras de tecnologias ambientais. O protecionismo do setor, ao mesmo tempo em que favorece a sobrevivência das empresas nacionais, limita o acesso às tecnologias externas mais sofisticadas.

Palavras-Chave: eco indústria, tecnologias ambientais, Brasil.

\section{Eco-Industry in Brazil: a characterization of the production sector of environmental technologies}

\begin{abstract}
The production sector of environmental technologies is essential for a country's economic and sustainable development, but there is not an accurate definition on environmental technologies, nor a delimitation of the sector, what prevents the progress of negotiations as the trade liberalization of such technologies. Thereby, this paper aimed to characterize the production sector of environmental technologies in Brazil in the light of studies already performed, by applying field research methodology in companies that attended FIMAI (International Fair and Seminar of Industrial Environment and Sustainability). Some findings reported the maintenance of certain aspects of the sector. Among them, there are effluents and wastes treatment as the main operating segments, polluting industries (chemical, steel and food industries) as major clients, environmental regulation as the main determining factor and domestic market as the prevailing one. The pervasive presence of national and small/medium-size companies is in line with the information found in the 2000's. Other findings brought relevant contributions, such as the high breakthrough effort from national companies, the businesses' operations in preventive and/or integrated technologies and the operation weaknesses of the government in acquisitions of environmental technologies. The protectionism of the sector, while favors the survival of national companies, limits the access to more refined external technologies.
\end{abstract}

Key-Words: eco-industry, environmental technologies, Brazil.

JEL Q55

\footnotetext{
${ }^{1}$ Professora Dra. do Departamento de Economia da UNESP

${ }^{2}$ Graduando do Curso de Economia da UNESP

${ }^{3}$ Graduanda do Curso de Economia da UNESP
} 


\section{Introdução}

A geração e o desenvolvimento de tecnologias ambientais, ao mesmo tempo em que previnem e tratam os danos ambientais decorrentes das atividades econômicas, são essenciais para o desenvolvimento econômico, com desdobramentos importantes na configuração da estrutura produtiva e social de um país. Também constituem fatores de estímulo à inovação e à competitividade, possibilitando desagregar crescimento econômico de degradação ambiental (ABDI, 2012).

Como reflexo, o fortalecimento do setor produtor de tecnologias ambientais tem sido visto como uma oportunidade para revigorar o crescimento econômico e uma janela para sair de crises, visto que é capaz de impulsionar novos negócios e gerar empregos. Países como Estados Unidos (EUA), China e Reino Unido lançaram vários programas com vistas a reequilibrar estratégias econômicas, regionais e sociais voltadas ao crescimento interno ambientalmente sustentável (Shapira et al., 2014).

Em consequência, o mercado mundial de tecnologias ambientais tem crescido significativamente, sendo estimado em torno de US\$ 800 bilhões em 2009 (ABDI, 2012). Apesar de a maior parte desse valor se concentrar nos países desenvolvidos, os países em desenvolvimento apresentaram potencial significativo, pois a taxa de crescimento anual desses mercados foi de $7 \%$ a 12\% entre 2000 e 2010, mas ainda estão protegidos por tarifas de importação (Simon, 2014).

Neste cenário, em 2001 a Declaração da Rodada Doha da Organização Mundial do Comércio (OMC) determinou a queda de barreiras comerciais sobre estes bens, mas as negociações se encontram num impasse por causa da ausência de definição do conceito de bens ambientais e de interesses divergentes (Neto, Rios, \& Velloso, 2006).

Na literatura e no seio das organizações internacionais não há consenso quanto ao que sejam tecnologias ambientais e, consequentemente, quanto às firmas e produtos que integram o setor. Shapira et al. (2014) mostraram que não há um padrão metodológico para delimitar o setor em pesquisas realizadas para países desenvolvidos. No Brasil, há dois principais estudos com a mesma meta: Tigre (1994) descreveu o setor a partir de pesquisa de campo e ABDI (2012) fez uma investigação por meio das principais firmas de segmentos ambientais e por meio de classificações de atividades econômicas.

No sentido de contribuir com novos subsídios para cobrir essa lacuna, o objetivo deste trabalho é caracterizar o setor produtor de tecnologias ambientais no Brasil à luz dos estudos anteriores, por meio de pesquisa de campo. Para tanto, este trabalho se divide em quatro seções, além desta introdução e da conclusão. Na seguinte, realiza-se uma discussão teórica a respeito da definição de tecnologias ambientais e seus fatores determinantes; a terceira sintetiza o contexto internacional e nacional do setor produtor de tecnologias ambientais, aqui chamado de Eco Indústria; na quarta, apresenta-se a metodologia e na última discutem-se os resultados.

\section{Tecnologias ambientais: referencial teórico}

Existe uma diversidade de termos que buscam caracterizar as tecnologias ambientais, o que reflete uma imprecisão conceitual. Apesar disso, é possível identificar alguns tipos mais citados e os principais fatores determinantes da geração e do desenvolvimento das tecnologias ambientais.

Jabbour (2010) levantou dezesseis nomenclaturas, na literatura nacional e internacional, que reportam à tecnologia ambiental: tecnologias ambientais alternativas; tecnologias ambientalmente interessantes; tecnologias verdes; tecnologias ambientalmente amigáveis; eco tecnologias; inovações tecnológicas ambientalmente saudáveis; tecnologias limpas; tecnologias mais limpas; tecnologias ambientalmente sensíveis; tecnologias ambientalmente avançadas; tecnologias naturais avançadas; soluções ambientalmente amigáveis; tecnologias ambientalmente benéficas; tecnologias mais verdes; tecnologias não agressivas ao meio ambiente; e tecnologias ambientalmente sustentáveis. 
Especificamente quanto ao referencial teórico relacionado ao tema, vários autores buscam definir e classificar as tecnologias ambientais. Para Lustosa (1999), o termo tecnologia ambiental é bastante amplo, utilizado para definir tecnologias direcionadas à melhoria do meio ambiente e envolve tecnologias que previnem danos ambientais e poupam recursos naturais, bem como as despoluentes. Para a autora, o conceito inclui tecnologias que não foram desenvolvidas para fins exclusivamente ambientais, como a nanotecnologia e a biotecnologia, que aumentariam o controle sobre as emissões e reduziriam o uso de pesticidas, por exemplo.

Kemp e Foxon (2007) relativizam o conceito, ao considerar tecnologias ambientais aquelas cuja utilização é menos prejudicial ao meio ambiente do que as alternativas relevantes.

De acordo com a ONU (1992), e como consta na Agenda 21, as tecnologias ambientalmente saudáveis protegem o meio ambiente, mitigam a emissão de poluentes, usam recursos de forma mais sustentável, reciclam mais seus resíduos e produtos, a fim de serem utilizados como inputs na cadeia produtiva da empresa, e buscam um tratamento dos dejetos menos danoso ao meio ambiente do que outras tecnologias.

Kuehr (2007), a partir de uma visão mais dinâmica, considera que as tecnologias ambientais fomentam a melhoria contínua de processos, produtos e serviços por meio da conservação de matérias-primas e energia, reduzindo o consumo, desperdícios e poluição durante todo o ciclo de vida produtivo.

Outra definição também parte do ciclo de vida do produto, mas inclui diferentes elementos, como hardwares, softwares e serviços. Para Shrivastava (1995) tecnologias ambientais são não só equipamentos de produção, mas também métodos e procedimentos, designs de produto e mecanismos de entrega de produtos que conservam energia e recursos naturais, minimizam o peso ambiental das ações humanas e protegem o ambiente natural.

Quanto à tipologia, Kemp e Arundel (1998) apresentaram duas amplas categorias de tecnologias ambientais conforme sua motivação e propósito de aplicação: tecnologias de fim de linha (end-of-pipe), associadas à remediação e gestão da poluição; e tecnologias limpas (clean technologies), de caráter preventivo e que reduzem a produção de emissões. detalhando:

Lustosa (1999), a partir de uma abordagem mais completa, aprofunda essa classificação

- Tecnologias para despoluir o ambiente (cleaning technologies), que são consideradas tecnologias de remediação, ou seja, elas são utilizadas depois que a poluição já ocorreu;

- Tecnologias poupadoras de recursos naturais (environment-saving technologies), que utilizam menos insumos, como matéria-prima ou energia;

- Tecnologias mais limpas (cleaner technologies), que apresentam um coeficiente de emissão de poluentes por unidade de produto inferior à outra tecnologia utilizada anteriormente, elas modificam o processo produtivo e também podem ser consideradas tecnologias de prevenção da poluição;

- Tecnologias de controle, que são utilizadas para monitorar os níveis de emissões e a degradação dos recursos naturais, como satélites para identificar os desmatamentos e queimadas bem como equipamentos de medição de emissões industriais.

Kuher (2007) associa os tipos ao grau de inovação das tecnologias ambientais, se incrementais ou radicais. Dessa forma, o autor propõe quatro categorias de tecnologias ambientais: tecnologias de controle da poluição e tecnologias mais limpas - citadas anteriormente - e tecnologias de mensuração ambiental e de impacto nulo. A tecnologia de mensuração difere de outras por não focar na redução dos impactos ambientais, mas sim na análise de como o meio ambiente tem se alterado e nas alternativas para corrigi-lo; enquanto isso, tecnologias de impacto nulo são aquelas que, além de proteger o meio ambiente, não geram impacto algum durante seu processo produtivo.

Klassen e Whybark (1999) apud Jabbour (2010) adicionam a gestão ambiental às categorias de controle e prevenção. Os autores tratam sistemas de gestão ambiental como uma tecnologia organizacional e os definem como investimentos que melhoram a forma como os aspectos ambientais são incorporados à manufatura e à organização como um todo. 
Embora não se trate especificamente de tecnologias ambientais, alguns autores utilizam a classificação de bens e serviços ambientais (BSA) como uma proxy. Entende-se por BSA aqueles produtos e serviços que medem, previnem, limitam, minimizam ou corrigem danos ambientais na água, ar e solo bem como problemas relacionados a resíduos. Isto inclui tecnologias limpas, produtos e serviços ambientais (OECD, 2005). Essas atividades são apresentadas por meio de listas extensas de itens propostas por organizações internacionais, como Organização para Cooperação Econômica e Desenvolvimento (OECD) e Acordo de Cooperação Econômica Ásia-Pacífico (APEC). Tais listas classificam mais de 100 bens ambientais por meio de códigos de comércio internacional, que apresentam três categorias: gestão da poluição, tecnologias limpas e gestão de recursos naturais (Sugathan, 2013).

Portanto, podemos tratar as tecnologias ambientais de forma ampla, como sendo constituídas por produtos, processos, serviços, sistemas organizacionais, hardwares e softwares que servem para proteger o meio ambiente, no sentido de monitorar, evitar, minimizar e reduzir os danos ambientais bem como permitir a conservação dos recursos naturais ao longo do ciclo produtivo. Embora haja uma variedade de termos citados pela literatura e por organizações internacionais, aqui a expressão "tecnologia ambiental” será utilizada para representar os demais, inclusive bens e serviços ambientais.

Quanto aos fatores determinantes da geração e desenvolvimento de tecnologias ambientais, destacam-se as políticas públicas. O governo desempenha um papel fundamental por meio da regulação ambiental, que fomenta a adoção de tecnologias ambientais pelas firmas, do suporte econômico e do poder de compra público (Jabbour, 2010).

A regulação ambiental exerce uma pressão sobre as empresas poluidoras que, para se adequar às regras, desenvolvem inovações e/ou buscam fornecedores de tecnologias ambientais gerando demanda para esses produtores. Conforme Romeiro e Salles Filho (1999), a restrição ambiental é uma fonte de oportunidades tecnológicas: num primeiro momento a inovação de tecnologias ambientais depende de medidas coercitivas, que embutem custos; mas, num segundo momento, passa a ser desenvolvida de forma espontânea pelas empresas, deixando de ser vista como uma fonte de custos.

No mesmo sentido, Kemp e Arundel (1998) apresentaram a reação das empresas às regulações como um processo dinâmico e evolutivo, caminhando, ao longo do tempo, de uma estratégia defensiva por parte das firmas reguladas ao nascimento de setores produtores de tecnologias ambientais, conforme Quadro 1 abaixo.

Quadro 1. Estratégias e estágios de respostas tecnológicas às pressões ambientais

\begin{tabular}{|l|l|}
\hline ESTRATÉGIAS & ESTÁGIOS DE POLÏTICAS DAS FIRMAS \\
\hline Estratégia indiferente & $1^{\mathrm{O}}$. não responde \\
\hline Estratégia defensiva & $\begin{array}{l}2^{\mathrm{O}} \text {. Pesquisa e Desenvolvimento (P\&D) concentrado em pequenas mudanças de } \\
\text { produto e processo }\end{array}$ \\
\hline Estratégia ofensiva & $\begin{array}{l}3^{\mathrm{O}} \text {. Pesquisa e Desenvolvimento (P\&D) focado sobre o desenvolvimento de novos } \\
\text { produtos sem grandes mudanças } \\
4^{\mathrm{O}} \text {. Pesquisa e Desenvolvimento (P\&D) focado sobre novos produtos e processos }\end{array}$ \\
\hline Estratégia inovativa & $\begin{array}{l}5^{\mathrm{O}} \text {. Pesquisa e Desenvolvimento (P\&D) para o desenvolvimento de alternativas } \\
\text { radicais } \\
6^{\mathrm{O}} \text {. Novos setores industriais e sistemas de produto }\end{array}$ \\
\hline
\end{tabular}

Fonte: Kemp e Arundel (1998).

A OECD (1999) estabeleceu uma relação entre diferentes instrumentos de política ambiental e as reações por tipos de firmas. Observou-se que quanto mais rigorosos os instrumentos de regulação ambiental - como padrões de produtos, de performance e especificações tecnológicas, que limitam as opções das firmas reguladas - maior foi o estímulo para o setor produtor de tecnologias ambientais, conforme Quadro 2 abaixo. Já os instrumentos econômicos, por serem mais flexíveis, como taxas, comércio de emissões e difusão de informações, tenderam a gerar pouca 
demanda para o setor de tecnologias ambientais, visto que as firmas reguladas são capazes de reagir sem a necessidade de gerar novos bens ou serviços ${ }^{4}$.

Quadro 2. Instrumentos de política ambiental e efeito sobre tipos de firmas

\begin{tabular}{|c|c|c|c|}
\hline & Firmas reguladas & Novas entrantes & $\begin{array}{c}\text { Firmas de tecnologias } \\
\text { ambientais }\end{array}$ \\
\hline Padrões de produtos & $\mathrm{XX}$ & $\mathrm{XX}$ & $\mathrm{XXX}$ \\
\hline Aprovação pré-mercado & $\mathrm{XXX}$ & $\mathrm{X}$ & $\mathrm{X}$ \\
\hline Produtos proibidos & $\mathrm{XXX}$ & $\mathrm{XXX}$ & $\mathrm{XX}$ \\
\hline Padrões de performance & $\mathrm{XX}$ & $\mathrm{XXX}$ & $\mathrm{XXX}$ \\
\hline Especificações tecnológicas & $\mathrm{XX}$ & $\mathrm{X}$ & $\mathrm{X}$ \\
\hline Permissões & $\mathrm{X}$ & $\mathrm{X}$ & $\mathrm{X}$ \\
\hline Taxas de poluição & $\mathrm{XXX}$ & $\mathrm{X}$ & $\mathrm{X}$ \\
\hline Comércio de emissões & $\mathrm{XXX}$ & $\mathrm{XXX}$ & $\mathrm{XX}$ \\
\hline Responsabilidade produtiva & $\mathrm{XXX}$ & $\mathrm{X}$ & $\mathrm{X}$ \\
\hline Difusão de informações & $\mathrm{XXX}$ & $\mathrm{X}$ & $\mathrm{XX}$ \\
\hline Acordos voluntários & & & \\
\hline
\end{tabular}

$\mathrm{X}=$ baixo; $\mathrm{XX}=$ médio; $\mathrm{XXX}=$ alto

Fonte: Heaton (1997) apud OECD (1999)

Em termos de suporte, Jabbour (2010) ressalta a importância de políticas que estimulem o setor, por meio da inserção da dimensão ambiental na Política de Ciência e Tecnologia (C\&T) de um país. Para o autor, tal inserção deve ocorrer por meio da discussão de tecnologias ambientais nos diversos níveis dos entes governamentais (estratégia de C\&T, instrumentos de Política de C\&T e resultados) e no conjunto de ações de cada uma dessas esferas. De tal modo, devem ser fornecidas pelo governo formação de recursos humanos, estrutura para pesquisa e articulação de redes de cooperação, difundindo centros de pesquisa e desenvolvimento para as firmas obterem vantagens financeiras.

Desta forma, de um lado a pressão da política ambiental tem um efeito indireto estimulante sobre o setor produtor de tecnologias ambientais gerando demanda a partir da reação das empresas reguladas, de outro, Políticas de C\&T contribuem para fomento do setor.

\title{
3. Eco Indústria: contexto mundial e nacional
}

Assim como não há consenso sobre um conceito de tecnologias ambientais, não existe uma definição consensual ou delimitação do setor produtor de tecnologias ambientais, também chamada de indústria de bens e serviços ambientais e eco indústria. Eco Indústria é o termo que será utilizado neste trabalho. Há, contudo, alguns recortes que têm sido utilizados pela OECD e OMC como ponto de partida para algumas discussões e dimensão deste mercado.

Conforme OECD (2005, p.2):

\begin{abstract}
A indústria de bens e serviços ambientais consiste de atividades que produzem bens e serviços usados para medir, prevenir, limitar, minimizar ou corrigir danos ambientais sobre a água, a atmosfera e o solo, assim como os problemas relacionados aos resíduos, ruídos e os ecossistemas. Isto inclui tecnologias limpas, produtos e serviços que reduzem riscos ambientais e minimizam a poluição e uso dos recursos.
\end{abstract}

Segundo a UNIDO (2011), a Eco Indústria é constituída pela produção e pelo desenvolvimento industrial que não impõem custos à saúde ou aos sistemas naturais ou trazem resultados adversos à saúde humana. No nível industrial, isto envolve a existência de indústrias que estão se "esverdeando" e a criação de novos setores verdes.

Para Jabbour (2010), se há uma tipologia de tecnologias ambientais, também é válida a existência de diferentes categorias de firmas desenvolvedoras dessas tecnologias. Tecnologias de controle e prevenção tendem a ser desenvolvidas por empresas ambientalmente intermediárias,

\footnotetext{
${ }^{4}$ Os instrumentos de política ambiental podem ser classificados entre regulação ambiental, mais rigorosa e eficiente por impor multas aos agentes poluidores, e instrumentos econômicos, mais flexíveis por afetar o cálculo econômico dos poluidores, como taxas de emissão, tarifas sobre efluentes, comércio de licenças para poluir (ALMEIDA, 1998).
} 
baseadas em engenharia que alteram seus produtos convencionais para produtos ambientalmente melhorados, como conversores de energia solar e baterias recarregáveis. As tecnologias de impacto nulo concentram-se em empresas ambientalmente intensivas, que possuem uma visão sistêmica da inserção da dimensão ambiental em seus negócios e cuja atuação é inerente ao desenvolvimento de tecnologias ambientais. Exemplos de tecnologias desse grupo são produtos para tratamento de efluentes e tecnologias alternativas radicais. Por fim, tecnologias de mensuração ambiental e sistemas de gestão tendem a ser desenvolvidos por fornecedores de serviços ambientais, como produtoras de vídeos, softwares para análise do ciclo de vida do produto e instituições financeiras ambientais. Podem ser firmas manufatureiras ou gerenciadoras de informação.

Apesar da falta de uma delimitação conceitual, é interessante realizar uma breve síntese da evolução e da estrutura atual da Eco Indústria no mundo e no Brasil.

A Eco Indústria surgiu como resposta às regulações ambientais rigorosas dos anos 1970/80. Conforme Barton (1998), nos anos 1970 foram implementadas regulações para as indústrias mais poluidoras, sobretudo nos países desenvolvidos, o que as levou a adotar tecnologias de tratamento e redução das emissões. Firmas envolvidas em outras atividades tornaram-se fornecedoras desses equipamentos, diversificando seus negócios, mas também se estabeleceram pequenas e médias empresas e consultorias. Posteriormente, algumas multinacionais ocuparam esse lugar, como Dow, Du Pont e Waste Management Technologies, e as grandes empresas se expandiram no mercado internacional.

As pioneiras nesse processo foram as empresas dos EUA, Japão e Alemanha nos anos 1980, como resposta, respectivamente, às regulações para tratamento de resíduos, poluição atmosférica e tratamento de água. Isso lhes deu vantagens competitivas nesses ramos, de modo que a Alemanha se tornou líder na produção de equipamentos para tratamento de água e o primeiro país do mundo a exportar essa tecnologia, especialmente para outros países da Europa, América do Norte, Oriente Médio, entre outros (Barton, 1998).

Com relação à região latino-americana, o aumento dos problemas sociais e ambientais levou os países a criar ou modernizar suas legislações ambientais nos anos 1975-95, com base nos padrões americanos, alemães e franceses. Porém, sua implementação continuou insuficiente na região. A abertura econômica, a privatização e a estabilidade dos países da região favoreceram o setor ambiental, mas somente após a segunda metade dos anos 1990 os países passaram a investir na recuperação ambiental, especialmente por meio das pressões regulatórias ambientais públicas. Como consequência, a partir desse período foi acentuada a demanda por tecnologias ambientais (Ansanelli, 2008).

Como resultado, o mercado mundial de tecnologias ambientais vem apresentando um crescimento significativo nas últimas décadas, visto que seu tamanho em 2010 era 177\% maior do que em 1993. Mais recentemente, o valor comercializado passou de US\$550 bilhões em 2003 para mais de US\$700 bilhões em 2013. O comércio de tecnologias ambientais representou 4,5\% do comércio mundial de bens com tendência semelhante, pois registrou um crescimento em torno de 10\% entre 2002 e 2013 (ABDI, 2012; Nascimento, 2015).

Os setores de maior comercialização mundial nos anos 1990 foram tratamento de efluentes líquidos, monitoramento ambiental e gestão de resíduos sólidos, respectivamente com 34\%, 15\% e $13 \%$ de participação no total vendido (Ansanelli, 2008). No período mais recente esse cenário mudou um pouco, visto que os grupos de produtos envolvidos na gestão da poluição (efluentes, ruídos e resíduos sólidos) se mantiveram no ranking, mas a produção de energia renovável assumiu o segundo lugar entre as tecnologias mais comercializadas pelos países em geral (Nascimento, 2015).

Nesse cenário, os principais atores vêm sendo os países desenvolvidos, responsáveis por $73 \%$ do total das exportações de bens ambientais. Nos anos 1990, os principais traders de tecnologias ambientais foram Europa Ocidental, Ásia e América do Norte, tendo a Europa como líder nesse negócio, pois exportou cerca de US\$110 bilhões em média por ano. Na década de 2010, a ascensão chinesa nesse mercado merece destaque, pois o país ocupou o segundo lugar nas 
exportações mundiais - com 12\% do total mundial comercializado em 2013 - depois da Alemanha e superando Estados Unidos e Japão (Ansanelli, 2008; ABDI, 2012; Nascimento, 2015).

Os países em desenvolvimento, com exceção da China, se mantiveram importadores líquidos de bens ambientais nas últimas décadas, o que reflete um padrão norte-sul de comércio. Apesar disso, seu potencial de evolução é bastante significativo se comparado aos países desenvolvidos, pois a taxa de crescimento anual do mercado de bens ambientais dos países desenvolvidos foi de 1\%, entre 2000 e 2010, contra 7\% a 12\% para os países em desenvolvimento (ABDI, 2012; Nascimento, 2015).

Isso tem ocorrido porque o mercado de bens ambientais é mais maduro nos países desenvolvidos, enfrentando problemas de crescimento lento, enquanto é nascente nos países em desenvolvimento e cresce sob a influência das necessidades de gestão ambiental. A saturação do mercado ambiental nos países desenvolvidos reforça o interesse deles na abertura comercial para outras regiões (Neto, Rios, \& Velloso, 2006; ABDI, 2012). Barton (1998), inclusive, sugeriu que há um interesse no escoamento de tecnologias ambientais defasadas por parte de países desenvolvidos em direção aos mercados nascentes em desenvolvimento.

O Brasil, nesse contexto, assistiu ao aumento da degradação ambiental nos anos 1970, decorrente do processo de industrialização e urbanização, e passou a discutir e implementar sua legislação ambiental a partir dos anos 1980, constituindo um importante fator para o mercado ambiental. Nos anos 1950 havia algumas empresas no segmento de saneamento para atender o setor público, mas não eram fornecedores especializados. A criação das companhias estaduais de saneamento, por meio do Plano Nacional de Saneamento (PLANASA) nos anos 1970, deu maior impulso ao setor. Nos anos 1990, a expansão dos programas de saneamento pelos governos estaduais nos anos 1990, as privatizações e a aprovação de legislações ambientais mais rígidas acentuaram os investimentos no setor (Ansanelli, 2008).

Nos anos 2000, com a Política Nacional de Mudanças Climáticas (PNMC) e a Política Nacional de Resíduos Sólidos (PNRS) surgiu a expectativa de que tecnologias voltadas ao controle de emissões, fontes de energia renovável e resíduos sólidos fossem fomentadas (Ansanelli \& Nakano, 2016).

Com relação à participação do país no mercado mundial de tecnologias ambientais, ela reflete a condição dos países em desenvolvimento, pois representou cerca de $1 \%$ das exportações mundiais de tecnologias ambientais em 2013, mantendo a existência de déficits comerciais. Ao se tratar de categorias de produtos, a produção de energias renováveis se destacou, sendo o etanol considerado o bem ambiental que mais impulsionou as exportações brasileiras (Nascimento, 2015).

No entanto, essas evidências partem de classificações superficiais do setor. Há alguns estudos que tiveram o propósito específico de delimitar e caracterizar o setor produtor de tecnologias ambientais no Brasil por meio de metodologias particulares. Tigre (1994) realizou uma pesquisa de campo, por meio de aplicação de questionários e entrevistas em 108 firmas participantes da Feira de Equipamentos (ECOBRASIL) em São Paulo e da Feira de Tecnologias Ambientais (ECOTECH) no Rio de Janeiro em 1992. Constatou-se que, do total das empresas pesquisadas, $32 \%$ eram de capital nacional e o restante de capital estrangeiro, das quais a maioria era europeia e norte-americana e, em relação ao tamanho, a maior parte era de porte pequeno/médio. Quanto aos segmentos, $74 \%$ atendiam aos problemas de tratamento de efluentes e $51 \%$ à disposição de resíduos sólidos. As soluções tecnológicas mais frequentes basearam-se em tecnologias ambientais do tipo end-of-pipe (para 45\% dos entrevistados), tendo como principais clientes as indústrias química, alimentícia, petroquímica, de papel e celulose, têxtil e couros; o setor de telecomunicações, embora pouco poluidor, foi um dos únicos consumidores de tecnologias limpas. O mercado nacional foi o foco de atuação da maioria das empresas e as políticas ambientais, especialmente as taxas sobre emissões e regulações rígidas, foram os mecanismos mais efetivos da difusão das tecnologias ambientais no país.

Do ponto de vista do esforço tecnológico empreendido, as empresas demonstraram-se bastante empenhadas no desenvolvimento de novas tecnologias, visto que $26 \%$ declararam investir mais de $10 \%$ do faturamento em P\&D. As atividades inovativas foram desenvolvidas 
principalmente dentro da empresa, em parte porque as soluções ambientais eram novas e exigiram tecnologias distintas (Tigre, 1994).

A ABDI (2012) realizou um relatório detalhado do setor para o período mais recente. De acordo com esse estudo, que partiu da investigação das firmas produtoras de tecnologias ambientais, os segmentos mais relevantes do mercado no Brasil nos anos 2000 têm sido abastecimento e tratamento de água, gestão de resíduos, controle da poluição atmosférica, gerenciamento de resíduos sólidos e engenharia e consultoria ambiental.

O setor de água e tratamento de águas residuais tem recebido investimentos crescentes passando de $\mathrm{R} \$ 3$ bilhões para R $\$ 7,5$ entre 2003 e 2010, concentrando a maior fatia do investimento ambiental do Brasil. Quanto à configuração do setor, há três tipos de prestadores de serviços: empresas estaduais, com 75\% dos serviços; serviços públicos municipais e empresas privadas, que formam um grupo de cerca de 70 companhias que obtiveram concessões nos anos 1990. Ressalta-se que as empresas públicas convivem com o histórico de dificuldades financeiras, o que tem gerado oportunidades para firmas privadas, que vêm sendo fortalecidas pelas facilidades institucionais das leis das Concessões (1995), das Parcerias Público-Privadas (PPP) (2004), dos Consórcios Públicos (2005) e da Lei do Saneamento (2007). Em função desse quadro, grandes empresas passaram a investir no setor, por meio da criação de novas empresas, como a Foz do Brasil (do grupo Odebrecht) e a Cab Ambiental (do grupo Queiroz Galvão). Com relação à origem do capital, observou-se uma limitada participação de empresas multinacionais, que atuam no mercado principalmente via exportação de tecnologias mais avançadas. A maior presença de empresas nacionais no setor justifica-se pela proteção tarifária até os anos 1990. As empresas privadas que mais realizaram investimentos em 2010 foram a Foz do Brasil, Equipav, CAB, Grupo Águas do Brasil (ABDI, 2012).

No setor de recuperação de áreas contaminadas, embora a legislação sobre remediação de terras no Brasil seja limitada, acredita-se que as oportunidades tendem a se ampliar no médio longo prazo, por causa do crescente número de requisitos legais, em especial a Lei federal e a recente lei estadual de São Paulo. O mercado geral para as atividades de remediação de solos foi estimado em aproximadamente R\$ 1 bilhão, mobilizando em torno de 3.000 empresas, a maioria de pequeno porte, e operando com uma taxa média de crescimento de $20 \%$ ao ano. Com relação aos demandantes, o potencial de crescimento do mercado está vinculado principalmente à necessidade da indústria de mineração e siderurgia. Apesar da existência de capacidade local na produção de equipamentos, verificou-se a necessidade de expertise no gerenciamento, monitoração e desenvolvimento de soluções de baixo custo. Ressalta-se a baixa presença de empresas multinacionais, mas notou-se um movimento significativo de fusões nos últimos anos. Dentre as empresas com maior capacitação atuantes nestes segmentos, é possível mencionar a Essencis Remediação, a Cetrel Lumina e a Geoklock (ABDI, 2012).

Com relação ao controle da poluição atmosférica, em 2004 o mercado brasileiro desses produtos foi estimado em US\$ 70 milhões, mas especialistas projetaram que tende a aumentar $20 \%$ ao ano no futuro. As atividades que mais têm necessitado de equipamentos e serviços de controle da poluição do ar foram petroquímica, energética (incluindo o gás natural), de etanol, de cimento, metalúrgica e siderúrgica. No Brasil, há escassez dessas tecnologias e presença de plantas antigas, de modo que muitas empresas internacionais, como a FLSmith e a ERM, criaram operações ou compraram plantas existentes e vêm aplicando seus padrões ambientais globais. A maioria das tecnologias tem sido fornecida por empresas dos EUA e Europa por meio de parceiros locais estabelecidos. Além disso, um número significativo de organizações tem atividades principais em outros setores, como tratamento de água e remediação (Foz do Brasil e Cab Ambiental) (ABDI, 2012).

No gerenciamento de resíduos sólidos, a PNRS vem colocando vários desafios para o setor público e privado, fornecendo oportunidades tecnológicas. Em 2009, o mercado de resíduos urbanos e perigosos foi avaliado em $\mathrm{R} \$ 10$ bilhões. Grande parte dos serviços de gestão de resíduos está sob a responsabilidade dos municípios, mas algumas empresas privadas vêm participando do setor por meio de contratos e concessões. Apesar da forte presença de fabricantes brasileiros no 
setor, observou-se certa participação de empresas internacionais com tecnologia mais sofisticada principalmente no tratamento de resíduos perigosos. Com relação ao tamanho, empresas de grande porte com tecnologias de ponta concentram-se nas regiões metropolitanas e as de pequeno porte nas cidades menores. É interessante notar uma inovação caracterizada pela gestão integrada no tratamento e reaproveitamento de resíduos, que oferece soluções durante todas as etapas do processamento de resíduos, da qual se destaca a empresa de origem alemã Kuttner (ABDI, 2012).

Os principais usuários da aquisição de equipamentos e prestação de serviços na área de engenharia ambiental são o setor público, embora haja presença de empresas privadas de grande porte. Verificou-se que a maioria das empresas brasileiras não possui know how para executar serviços de consultoria ambiental mais complexos, o que justifica a presença das estrangeiras. Contudo, por determinação legal do país, as firmas estrangeiras são obrigadas a manter alguma representação local ou conexão com empresa nacional para participar do processo de licitação. Ao mesmo tempo, algumas dessas empresas mantêm as determinações ambientais das matrizes, facilitando a transferência de sistemas ambientais. Assim como no setor de controle da poluição atmosférica, muitas empresas atuam em diversos ramos e, semelhante às inovações no setor de tratamento de resíduos sólidos, a maioria das soluções são integradores de sistemas. É importante notar a significativa presença dos usuários na dinâmica inovativa do setor, dada sua complexidade (ABDI, 2012).

Na tentativa de fornecer informações adicionais sobre o valor da produção e o volume de emprego gerado pelo setor produtor de tecnologias ambientais, bem como delimitá-lo a partir de bases estatísticas oficiais, a ABDI (2012) apresentou uma classificação alternativa conforme a Classificação Nacional de Atividades Econômicas (CNAE 2.0) do Instituto Nacional de Geografia e Estatística (IBGE) conforme Quadro 3.

Essa classificação é reconhecidamente limitada, uma vez que a CNAE é bastante agregada e existem vários equipamentos considerados ambientais que se prestam a outros usos, de uso múltiplo, de modo que não podem ser adequadamente contabilizados. O mesmo vale para os serviços.

De qualquer modo, o estudo apontou que o setor de equipamentos apresentou baixo valor da produção com empresas de pequeno porte, cujo número de unidades e volume de emprego cresceu, respectivamente, 31,3\% e 30\% entre 2007 e 2009. Já o setor de serviços, com mais de 200 mil empregados e 4.000 unidades, teve um crescimento superior a 37\% de novos produtores entre 2007 e 2009 (ABDI, 2012).

Quadro 3. Classificação dos códigos da CNAE 2.0 das tecnologias ambientais

\begin{tabular}{|l|l|}
\hline ATIVIDADE & CNAE 2.0 \\
\hline Equipamentos & \\
\hline Fabricação de máquinas e equipamentos para saneamento básico e ambiental & 28259 \\
\hline Serviços & \\
\hline Gestão de redes de esgoto & 37011 \\
\hline Atividades relacionadas a esgoto, exceto a gestão de redes & 37029 \\
\hline Coleta de resíduos não perigosos & 38114 \\
\hline Coleta de resíduos perigosos & 38122 \\
\hline Tratamento e disposição de resíduos não perigosos & 38211 \\
\hline Tratamento e disposição de resíduos perigosos & 38220 \\
\hline Recuperação de materiais metálicos & 38319 \\
\hline Recuperação de materiais plásticos & 38327 \\
\hline Recuperação de materiais não classificados anteriormente & 38394 \\
\hline Descontaminação e outros serviços de gestão de resíduos & 39005 \\
\hline
\end{tabular}

Fonte: ABDI (2012)

Portanto, o nascimento e a evolução da Eco Indústria foram (e estão) significativamente associados às políticas ambientais - no mundo desde os anos 1970 e, no Brasil, principalmente a partir dos anos 1990. O mercado dos países desenvolvidos encontra-se maduro, enquanto que nos países em desenvolvimento, no caso, o Brasil, nascente e comercialmente protegido. Embora nos 
anos 2000 a maioria das empresas produtoras de tecnologias ambientais continuou sendo de pequeno/médio porte, como nos anos 1990, observou-se o crescimento da participação das empresas de capital nacional, mas as tecnologias mais sofisticadas dependeram de empresas transnacionais no país. A participação dessas empresas no setor esteve vinculada (ou limitada) aos processos de licitações e concessões. Uma inovação interessante foi o sistema de gestão integrada, porém, provavelmente devido à proteção tarifária, mantiveram-se os mesmos clientes e o mercado de destino.

\section{Metodologia}

Conforme constatado pela literatura, há uma dificuldade em estudar a Eco Indústria devido à falta de definição de tecnologias ambientais e do recorte setorial. Shapira et al. (2014) apresentaram algumas metodologias de pesquisa para identificar firmas verdes - algumas delas também utilizadas pelos autores discutidos anteriormente -, cada qual com suas vantagens e desvantagens. $\mathrm{O}$ uso de listas de classificações de tecnologias ambientais é direto e permite o uso de dados de emprego e de produção disponíveis em fontes oficiais, no entanto, algumas categorias de produto podem incluir diversas atividades que são de uso múltiplo, não exclusivamente ambiental. Outra forma é identificar as empresas do setor por meio de associações industriais, porém, essa técnica é limitada, pois muitos produtores de tecnologias ambientais não pertencem a estas instituições ou elas podem nem existir. Os métodos baseados em surveys (pesquisa de campo em uma população ou amostra) fornecem informações e dados adicionais às listas, mas envolvem tempo, custo e baixo nível de respostas.

A metodologia utilizada neste trabalho, inspirada em Tigre (1994) e embasada por Shapira et al. (2014), foi uma pesquisa de campo em empresas de tecnologias ambientais, por meio da aplicação de questionários fechados. O critério utilizado para delimitar o setor foi selecionar as empresas que participam da Feira Internacional de Meio Ambiente Industrial e Sustentabilidade (FIMAI), que ocorre anualmente em São Paulo e em 2015 teve sua décima sétima edição. A amostra de empresas que responderam ao questionário foi constituída por 30 - 20\% de um total de 150 expositores reunidos pela FIMAI - o que constitui uma amostra significativa. Algumas desvantagens desse tipo de método discutidas por Shapira et al. (2014), como gasto de tempo e baixo nível de respostas, foram minimizadas pela aplicação dos questionários durante a realização da FIMAI.

\section{Resultados}

Alguns resultados da pesquisa de campo apontaram para uma manutenção do setor conforme descrito pelos estudos anteriores, mas outros despertaram atenção frente à liberalização comercial de tecnologias ambientais. Em termos de controle de capital, para essa amostra, o setor ainda é dominado por empresas nacionais (66\%), como constatado pela ABDI (2012), sendo constituído principalmente por empresas de pequeno porte operando nos ramos industriais e comerciais. Nota-se que muitas empresas atuam em atividades de bens e serviços simultaneamente e em diversos segmentos, como evidenciado pelo Gráfico 1 e apontado pela literatura. O principal mercado das firmas, conforme identificado por Tigre (1994), continua sendo o nacional para a quase totalidade das empresas da amostra (92\%), refletindo a baixa participação do Brasil nas exportações mundiais de tecnologias ambientais.

O segmento de atuação mais significativo, como indicado pelos estudos de Tigre (1994) e ABDI (2012), é o de tratamento de água e esgoto industrial, não urbano, o que pode sugerir a efetivação dos investimentos projetados por empresas privadas nos anos 2000. Em seguida, destacaram-se consultoria e resíduos sólidos, este último provavelmente incentivado pela PNRS.

Gráfico 1 - Segmentos de atuação das empresas produtoras de tecnologias ambientais no Brasil 


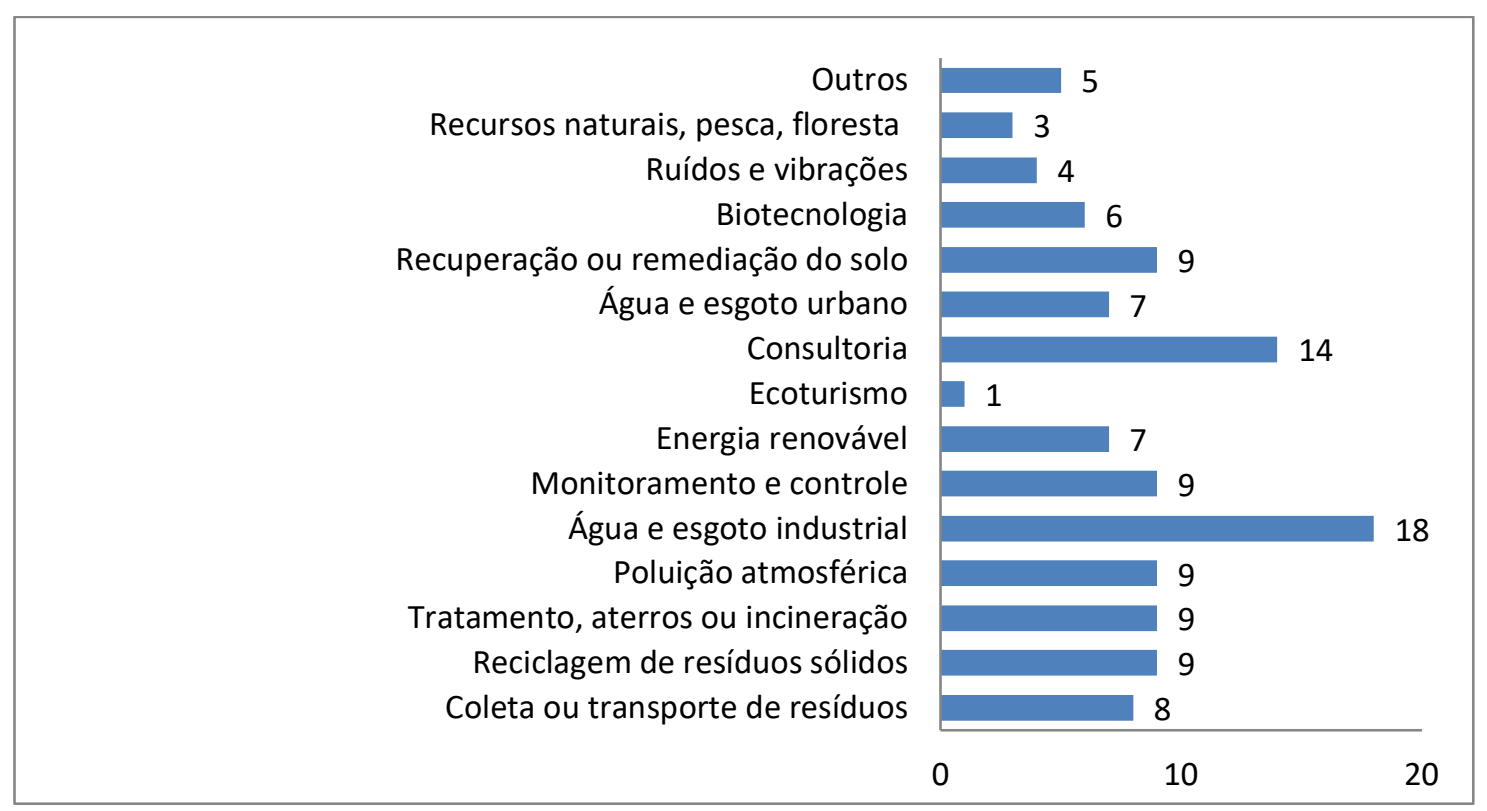

Fonte: respostas dos questionários

Em termos de clientes, para as empresas da amostra, destacaram-se os setores considerados mais poluidores do ponto de vista do processo produtivo e intensivos em recursos naturais de acordo com o Gráfico 2. Respectivamente, em ordem decrescente de importância nas respostas, foram citadas firmas químicas, petroquímicas, de alimentos e bebidas, farmacêuticas e de papel e celulose, conforme apontaram os estudos anteriores. Importante ressaltar os clientes menos indicados, como administração pública e agências de resíduos sólidos, o que sugere ausência de articulação direta entre políticas públicas ambientais e fornecedores de tecnologias ambientais, sobretudo ao se tratar da PNRS, ou aumento da presença de empresas privadas facilitada pelas concessões. Além disso, o papel das compras governamentais não foi significativo nesta pesquisa.

Gráfico 2 - Ramos de atuação dos clientes das empresas da amostra

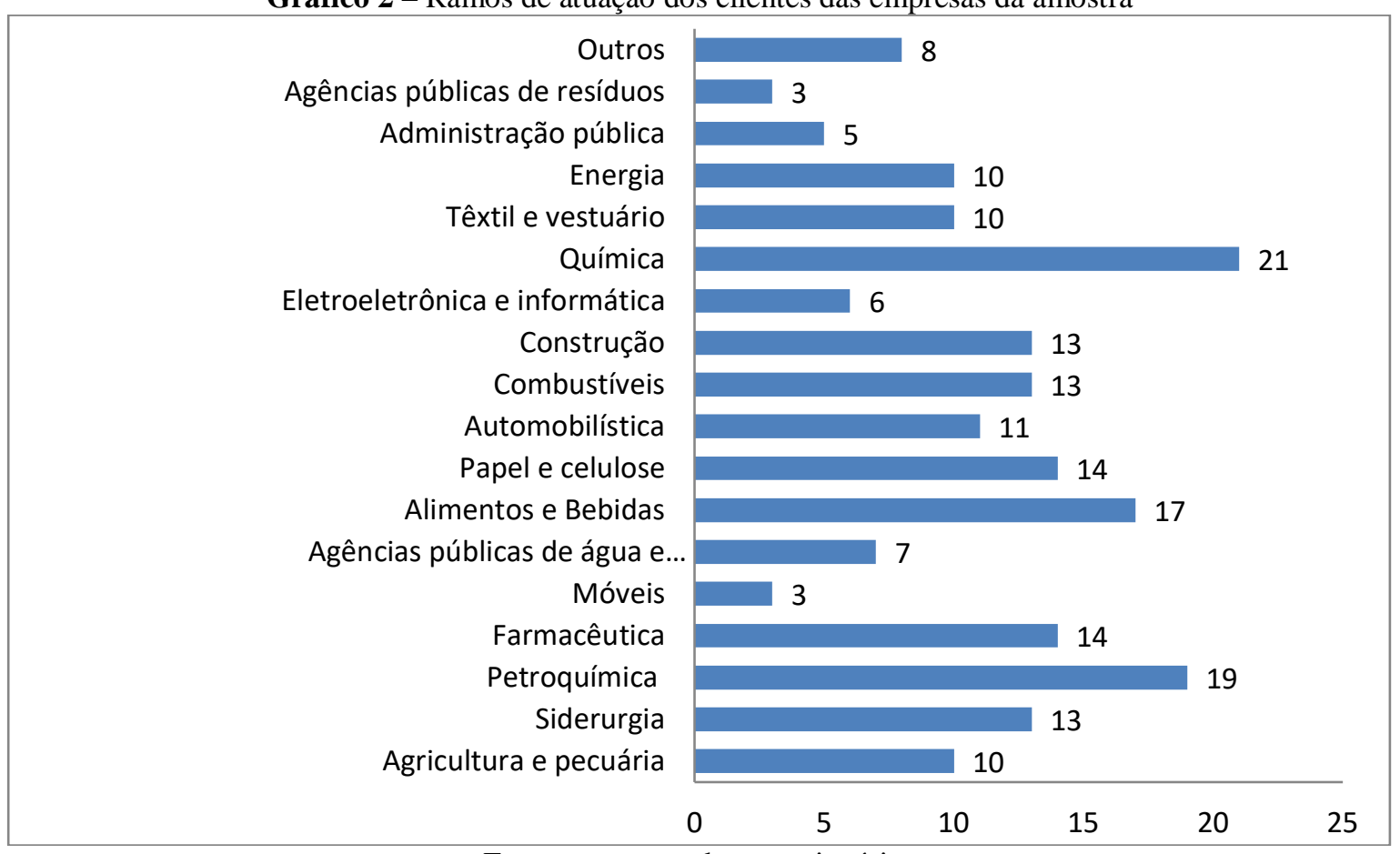

Fonte: respostas dos questionários 
Confirmando a relação teórica entre política ambiental e geração de tecnologia ambiental, as regulações ambientais nacionais foram apontadas como o primeiro determinante no estímulo do crescimento do setor e no desenvolvimento de inovações tecnológicas, seguidas pelas certificações, exigências dos clientes e normas voluntárias, conforme Gráfico 3. Essa constatação é coerente com o destino das tecnologias ambientais voltadas ao mercado interno.

Gráfico 3 - Fatores estimulantes do mercado de tecnologias ambientais para as empresas da amostra

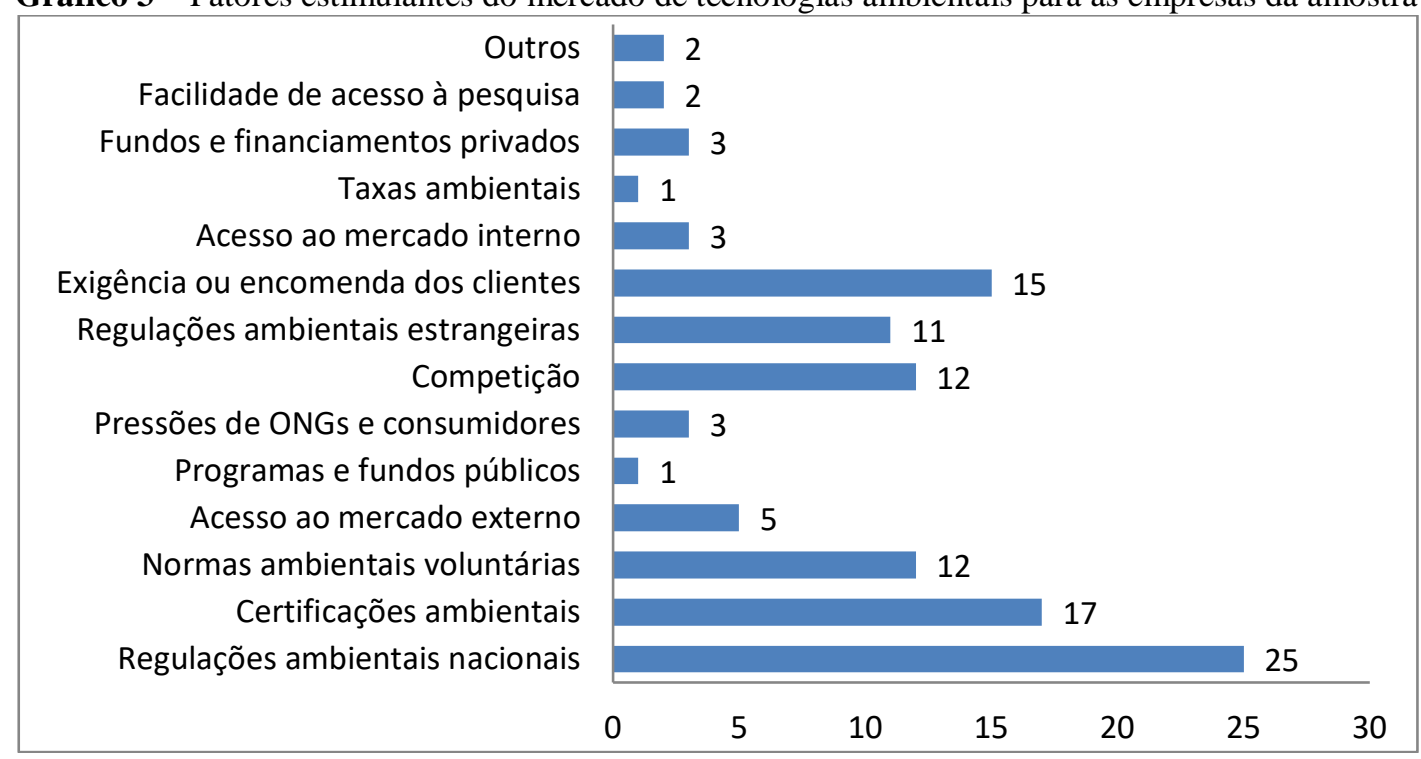

Fonte: respostas dos questionários

De outro lado, entre os obstáculos para ascensão do setor, as respostas que mais se repetiram foram recessão econômica, custos elevados e tarifas de importação, como mostra o Gráfico 4. Notase que, nesse caso, a proteção comercial não tem sido bem vista por essas empresas, talvez pela dificuldade no acesso às tecnologias ou equipamentos mais sofisticados disponíveis no mercado internacional.

Gráfico 4 - Obstáculos para a expansão do setor para as empresas da amostra

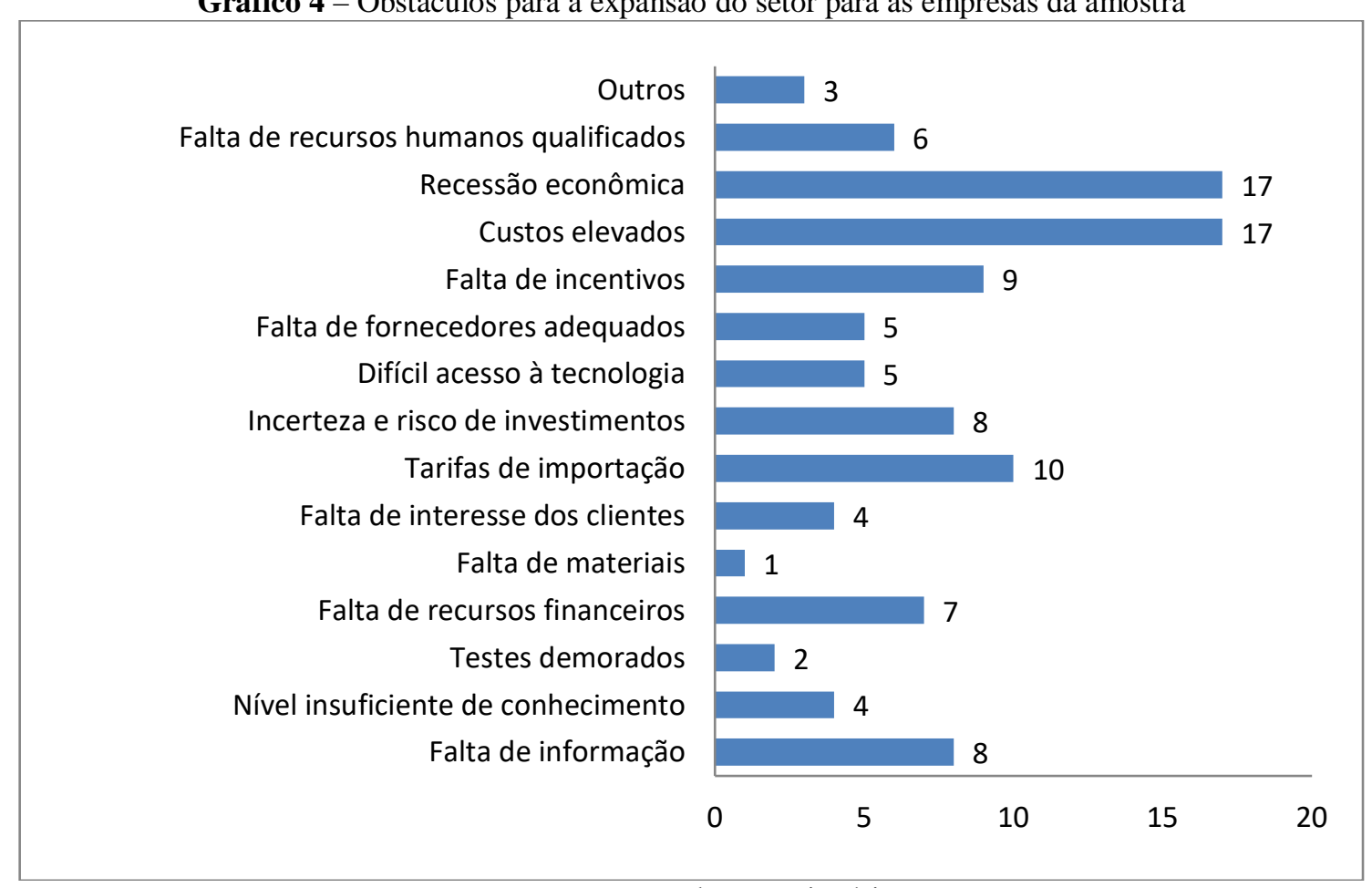

Fonte: respostas dos questionários 
Com relação à capacidade inovadora, os resultados surpreendem. Das empresas que responderam à questão, 81\% afirmaram realizar inovações tecnológicas, sobretudo na forma de novos produtos. Entre as atividades inovativas, destacaram-se gastos com P\&D interno, treinamento de pessoal, compras e cooperação com outras empresas, conforme os Gráficos 5 e 6.

Gráfico 5 - Tipo de inovação para as empresas da amostra

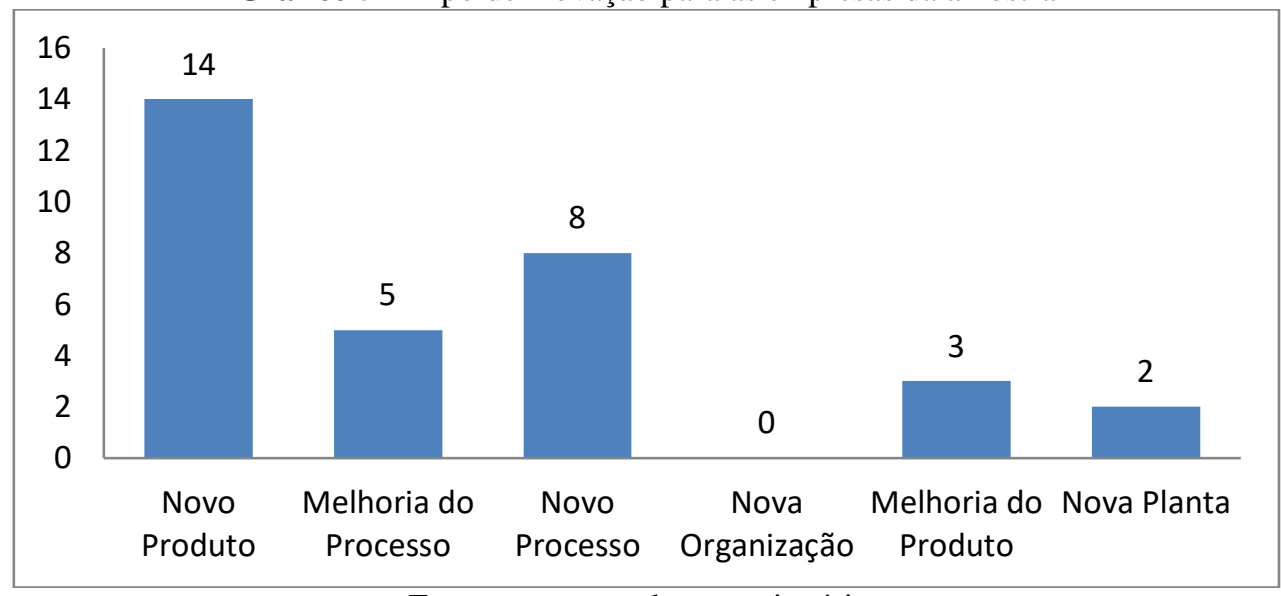

Fonte: respostas dos questionários

Gráfico 6 - Atividades Inovativas realizadas pelas empresas da amostra

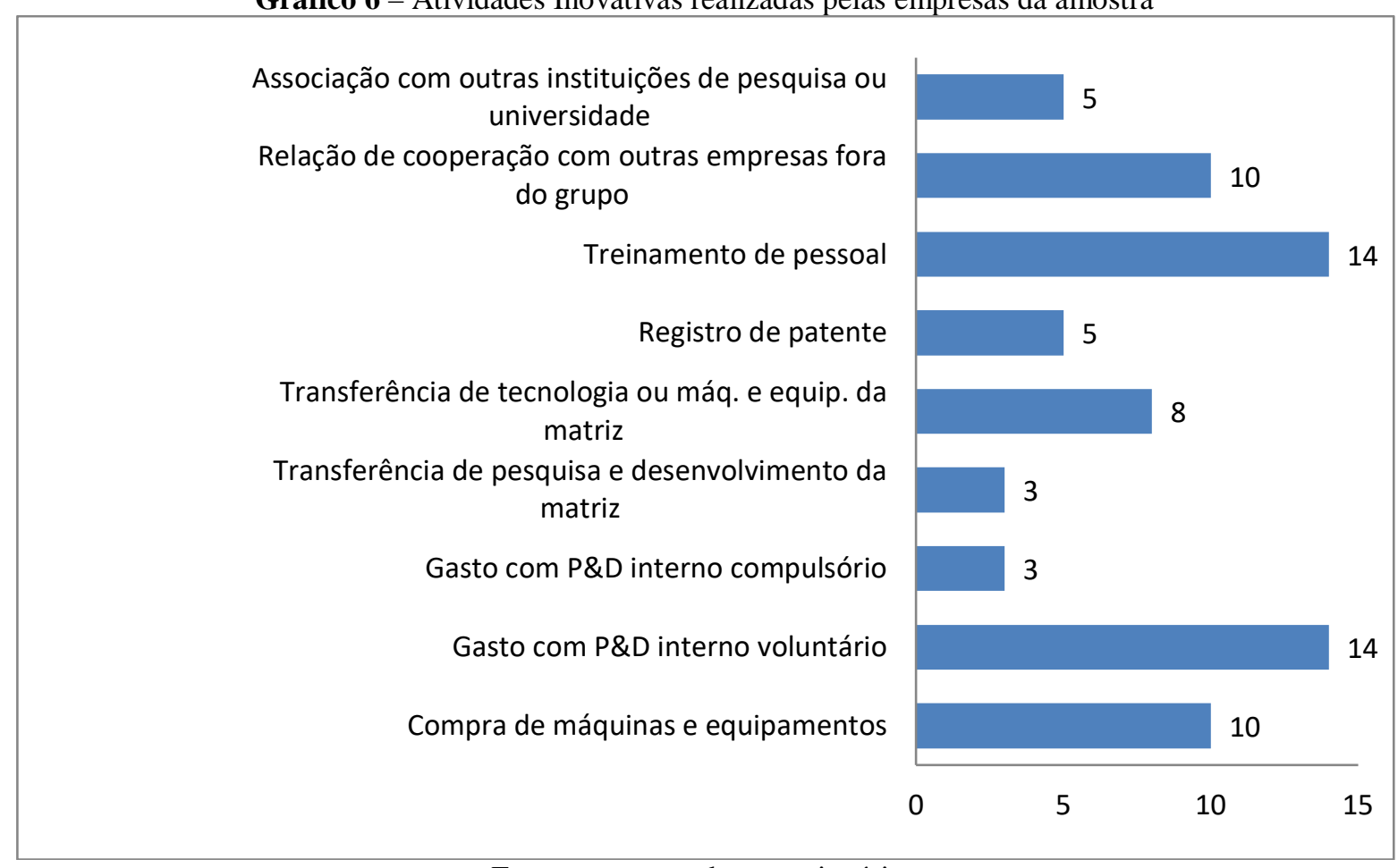

Fonte: respostas dos questionários

Algumas informações interessantes diferem dos estudos anteriores. Uma delas refere-se à elevada participação de empresas nacionais nesse contexto: das empresas que afirmaram ter realizado inovações nos últimos três anos, 13 eram nacionais e 9 estrangeiras; além disso, daquelas que realizaram dispêndios com P\&D, 8 eram nacionais e 5 estrangeiras. Ou seja, $61 \%$ das empresas nacionais inovadoras investiram em P\&D, contra 55\% das estrangeiras. Desse modo, apesar das dificuldades, tem havido um esforço inovador significativo por parte das firmas nacionais. Contudo, verificou-se pouca interação com universidades e baixo índice de registro de patentes.

Outra resposta que contrariou o estudo de Tigre (1994) trata da percepção das firmas quanto ao tipo de tecnologia ambiental de atuação. Entre as opções de prevenção (tecnologias limpas) e 
remediação (end-of-pipe), a grande maioria afirmou atuar na prevenção. Contudo, grande parte declarou atuar tanto na prevenção quanto na remediação, indicando uma direção em termos de soluções integradoras, conforme indicado pela ABDI (2012).

Quando perguntadas sobre os possíveis impactos da redução tarifária, a grande maioria acredita no crescimento das vendas domésticas e do volume de importação. Isso sugere que a proteção tarifária não é o principal motivo percebido pelas empresas para estímulo do mercado, mas provavelmente tem contribuído para o crescimento e/ou permanência de pequenas empresas nacionais e para o desenvolvimento de inovações. Contudo, devido à permanente evolução tecnológica, as altas tarifas podem dificultar o acesso das empresas a alguns equipamentos mais sofisticados que são escassos internamente, como apontado por ABDI (2012).

\section{Conclusão}

O objetivo deste trabalho foi caracterizar o setor produtor de tecnologias ambientais no Brasil, por meio de pesquisa de campo numa amostra de $20 \%$ das empresas que participaram da FIMAI em 2015. Do ponto de vista teórico, verificou-se a ausência de uma definição conceitual do que sejam as tecnologias ambientais, mas pode-se caracterizá-las por envolver produtos, processos, serviços, sistemas organizacionais, hardwares e softwares que servem para proteger o meio ambiente, no sentido de monitorar, evitar, minimizar e reduzir os danos ambientais bem como permitir a conservação dos recursos naturais. De modo amplo, elas foram classificadas como tecnologias de prevenção e de remediação de danos ambientais, cujo principal elemento estimulante tem sido a regulação ambiental, gerando demanda via pressão sobre os agentes poluidores.

Do ponto de vista da experiência internacional, o setor foi desenvolvido a partir da evolução de regras ambientais, tendo na Europa e nos EUA seus principais fornecedores de tecnologias e traders no mercado mundial. Recentemente assistiu-se à ascensão chinesa no comércio mundial. Os países em desenvolvimento têm seus mercados protegidos, são importadores líquidos, mas vêm apresentando forte potencial de crescimento, representando oportunidades aos setores mais maduros dos países desenvolvidos.

Internamente, alguns resultados da pesquisa demonstraram a manutenção de certos aspectos do setor. Entre esses encontram-se tratamento de efluentes e resíduos como os principais segmentos de atuação, setores poluidores (químico, siderúrgico, alimentício) como os maiores clientes, a regulação ambiental como principal fator determinante e o mercado interno como o predominante. A presença dominante de empresas nacionais e de pequeno/médio porte condiz com o verificado nos anos 2000. Outros resultados trouxeram contribuições importantes, devido ao elevado esforço inovador das empresas nacionais, a atuação das firmas nos tipos de tecnologias preventivas e/ou integradoras e a fragilidade de atuação do poder público nas compras de tecnologias ambientais. $\mathrm{O}$ protecionismo do setor, ao mesmo tempo em que favorece a sobrevivência das empresas nacionais, limita o acesso às tecnologias externas mais sofisticadas.

\section{Referências}

ABDI- ASSOCIAÇÃO BRASILEIRA DE DESENVOLVIMENTO INDUSTRIAL. Relatório de acompanhamento setorial: competitividade do setor de bens e serviços ambientais. ABDI-NEIT-IEUNICAMP, 2012.

ALMEIDA, L. T. Política ambiental: uma análise econômica. São Paulo : Papirus, 1998.

ANSANELLI, S. L. M. Os impactos das exigências ambientais europeias para equipamentos eletroeletrônicos sobre o Brasil. Campina : UNICAMP, 2008. Tese (Pós-Graduação em Desenvolvimento Econômico), Instituto de Economia, Campinas, São Paulo, 2015.

ANSANELLI, S. L. M.; NAKANO, P. Política industrial e política ambiental no Brasil: convergências e divergências durante os governos Lula e Dilma. In: Anais do II Encontro Nacional de Políticas Públicas (ENPP), Araraquara/SP, junho de 2016. 
BARTON, J. R. La dimension norte-sur de las industrial de limpieza ambiental y la disufión de tecnologías limpas. Revista de la CEPAL, n. 64, abril 1998.

JABBOUR, C. J. C. Tecnologias ambientais: em busca de um significado. Revista de Administração Pública, Rio de Janeiro : FGV, 44 (3), p. 591-611, maio/junho de 2010.

KEMP, R.; ARUNDEL, A. "Survey indicators for environmental innovation”. IDEA Paper, number 8, 1998.

KEMP, R.; FOXON, T. Typology of eco-innovation. In: MEI project: Measuring Eco-innovation. European Commission, ago. 2007.

KLASSEN, R. D.; WHYBARK, D. C. The impact of environmental technologies on manufacturing performance. Academy of Management Journal, v. 42, n. 6, p. 599- 615, 1999.

KUEHR, R. Environmental technologies: from a misleading interpretations to an operational categorization and definition. Journal of Cleaner Production, 2007.

LUSTOSA, M. C. Meio Ambiente, inovação e competitividade na industria brasileira: a cadeia produtiva do petróleo. Tese de doutorado. Rio de Janeiro: IE/UFRJ, 1999.

NASCIMENTO, R. M. O comércio internacional de tecnologias ambientais: a inserção do Brasil e da China. Araraquara: Unesp, 2015. Dissertação (Pós-Graduação em Economia), Faculdade de Ciências e Letras, UNESP, São Paulo, 2015.

NETO, A. J. M.; RIOS, S. P.; VELLOSO, E. Negociações sobre Bens Ambientais na OMC. Estudos CNI 7. Brasília, junho de 2006.

http://www.cni.org.br/portal/data/files/8A9015D01418E1EE01142D0E89E00111/Estudos\%20CNI \%207\%20-\%20Bens\%20ambientais\%20OMC.pdf. Acesso em maio de 2015.

OCDE. Environmental policies: technology effects. In: OCDE. "Technology and environment: towards policy integration”. Paris, 1999.

OCDE. Opening markets for environmental goods and services. Policy Brief, September, 2005.

ROMEIRO, A. R.; SALLES FILHO, S. Dinâmica de inovações sob restrição ambiental. In: ROMEIRO, A . R.; REYDON, B., P.; LEONARDI, M. L. A . (org.) Economia do meio ambiente: teoria, políticas e a gestão de espaços regionais. Campinas: Unicamp/IE, 1999.

SIMON, C. M. Bens e Serviços Ambientais nas Agendas Legislativa e da Diplomacia Comercial: do Nominalismo ao Pragmatismo. Brasília: Núcleo de Estudos e Pesquisas/CONLEG/Senado, mar./2014 (Texto para Discussão n-145). Disponível em: www.senado.leg.br/estudos. Acesso em 18 mar. 2014.

SHAPIRA, P.; GÖK, A.; KLOCHIKHIN, E.; SENSIER, M. Probing “green” industry enterprises in the UK: a new identification approach. Technological Forecasting \& Social Change, 85, p. 93-104, 2014.

SHRIVASTAVA, P. Environmental technologies and competitive advantage. Strategic Management Journal, Vol. 16, 183-200, 1995. 
SUGATHAN, M. Lists of Environmental Goods: as overview. Information Note. Internacional Centre for Trade and Sustainable. December, 2013.

TIGRE, P. B. (coord.). Tecnologia e meio ambiente: oportunidades para a indústria. Rio de Janeiro : Editora UFRJ, 1994.

UNIDO - UNITED NATIONS INDUSTRIAL DEVELOPMENT ORGANIZATION. Green industry: policies for suooporting green industry. Vienna, 2011.

ANEXO 1 - LISTA DAS EMPRESAS ACESSADAS

- Enviro Chemie Tratamentos Especializados LTDA;

- RGO (Fabricação de equipamentos tecnológicos);

- Eficienergy (Plataforma de gerenciamento e eficiência energética);

- Rochman Comércio de Equipamentos e Montagens

- HERING AG

- UNIAMBIENTAL Soluções em Resíduos LTDA;

- RENTALTECH Ambiental Comércio Importação Exportação LTDA;

- CMA Engenharia Ambiental LTDA;

- Dinâmica Ambiental;

- GLOTEC Controle de Odores;

- ORION

- BIOZYME Brasil;

- Premium Ambiental;

- SIR Company;

- UBA Ambiental;

- Alpina Briggs Defesa Ambiental S/A - Alpina Ambiental S/A;

- Suzaquim Indústrias Químicas LTDA;

- ENC ENERGY - Energia de novas gerações;

- Pieralisi;

- Sanwey Indústria de Containers LTDA;

- Plantec Laboratórios;

- ACQUASYS Laboratório de Análises Ambientais LTDA;

- AMBIENTAL MS

- EMEC do Brasil Comércio de Bombas e Equipamentos LTDA;

- ODOURNET Brasil LTDA;

- ES4i Environmental Services for Industries LTDA;

- BLOBEL Umwelttechnik GmbH;

- Haver \& Boecker / Ambievo;

- LUBVAP Distribuidora de Lubrificantes e Químicos;

- KOREN AMBIENTAL LTDA;

ANEXO 2 - Questionário

1) O número de empregados da tua empresa situa-se entre: (marque apenas uma opção)

Se é Indústria

( )até 19

()de 20 a 99

( )de 100 a 499

()mais de 500
Se é Comércio ou Serviços

( )até 9

()de 10 a 49

()de 50 a 99

()mais de 100

Saberia dizer um número aproximado dos empregados em todas as unidades no Brasil?

2) Sua empresa é: (marque apenas uma opção) 
3) Se o controle do capital é estrangeiro ou é filial, a região de origem é: (marque apenas uma opção)
( )América
( )Europa
( )EUA
( )Japão
( )Ásia
( )Oceania ou África

4) Sua empresa presta serviços ou oferece produtos na(s) área (s):

( )coleta ou transporte de resíduos urbanos ou industriais

( )reciclagem de resíduos sólidos urbanos ou industriais

( )tratamento, aterros ou incineração de resíduos sólidos urbanos ou industriais

( )poluição atmosférica

( )água e esgoto industrial

( )monitoramento e controle

( )energia renovável

( )eco turismo

( )consultoria

( )água e esgoto urbano

( )recuperação ou remediação do solo

( )biotecnologia

( )ruídos e vibrações

( )recursos naturais -pesca, floresta e agricultura sustentável ()outros

5) Qual é o código da Classificação Nacional de Atividade Econômica (CNAE) da tua empresa?_Apresentar a classe (5 dígitos)

6) Qual tem sido o principal mercado da sua empresa em faturamento nos últimos 3 anos? (marque apenas uma opção)
() nacional
( ) estrangeiro

7) Os principais clientes de tua empresa são da (s) atividade (s) de:
( )agricultura e pecuária
( )alimentos e bebidas ( )eletroeletrônica e informática
( )siderurgia
( )petroquímica
( )papel e celulose
( )química
( )farmacêutica
( )automobilística
( )móveis
( )combustíveis
( )construção
( )têxtil e vestuário
( )agências públicas de água e saneamento
( )energia
( )administração pública
( )agências públicas de resíduos

8) Você considera que tua empresa realiza que tipo de atividades ambientais:

( )prevenção (evita geração de impactos ambientais)

( )remediação (trata os efeitos dos impactos ambientais já gerados)

9) Nos últimos 3 anos sua empresa desenvolveu alguma inovação tecnológica:
( )sim
( )não
( )tentou mas não conseguiu
( )não sei

10) Se sim, de que tipo?

( )novo produto ( )novo processo ( )melhoria do produto

( )melhoria do processo ( )nova organização ( )nova planta

11) Se sim, de que modo?

( )compra de máquinas e equipamentos

( )gastos com Pesquisa e Desenvolvimento interno voluntários

( )gastos com Pesquisa e Desenvolvimento interno compulsório

( )transferência de pesquisa e desenvolvimento da matriz

( )transferência de tecnologia ou de máquinas e equipamentos da matriz

()registro de patentes

( )treinamento de pessoal

( )relações de cooperação com outras empresas fora do grupo

( )associação com instituições de pesquisa ou universidades 
12) Os gastos com Pesquisa e Desenvolvimento $(P \& D)$ necessários para realizar as inovações representaram (representam): (marque apenas uma opção)

( )menos de 2,5\% dos gastos totais com P\&D ( )entre 2,5\% e 5\% dos gastos totais com P\&D

( )entre $5 \%$ e $10 \%$ dos gastos totais com P\&D ( )mais de $10 \%$ dos gastos totais com P\&D

13) Na sua opinião, os principais motivos que vem estimulando o mercado e a geração das inovações da tua empresa são:

( )regulações ambientais nacionais

( )regulações ambientais estrangeiras

( )certificações ambientais

( )normas ambientais voluntárias

( )exigência ou encomenda dos clientes

( )acesso ao mercado externo

( )acesso ao mercado interno

( )programas e fundos públicos

( )pressão de ONGs e consumidores

( )competição

( )taxas ambientais

( )fundos e financiamentos privados

( )facilidade de acesso à pesquisa

( )outros

14) Quais têm os principais obstáculos enfrentados pela tua empresa para expandir os negócios?

( )falta de informação

( )incerteza e riscos de investimentos

( )nível insuficiente de conhecimento

()testes demorados

()falta de recursos financeiros

()difícil acesso à tecnologia

( )falta de materiais

( )falta de fornecedores adequados

( )falta de interesse dos clientes

()falta de incentivos

( )custos elevados

( )tarifas de importação

( )outros

( )recessão econômica

( )falta de recursos humanos qualificados

15) Atualmente a tarifa de importação de bens ambientais no Brasil é de aproximadamente $14 \%$. Você acredita que a redução desta tarifa de importação teria que tipo de efeito sobre o mercado no Brasil?
importações
( )aumento
( )queda
( )queda
( )sem efeito
( )não sei
exportações
( )aumento
( )sem efeito
( )não sei
vendas domésticas
( )aumento
( )queda
( )sem efeito
( )não sei

outros

Comentários: 